\title{
Distinct Expression Patterns of Two Tumor Necrosis Factor Superfamily Member 15 Gene Isoforms in Human Colon Cancer
}

\author{
Tomasz Jerzy Ślebioda ${ }^{1}$ (1) - Marcin Stanisławowski ${ }^{1} \cdot$ Marta Cyman $^{1}$ • Piotr Mieczysław Wierzbicki ${ }^{1}$. \\ Dorota Żurawa-Janicka ${ }^{2} \cdot$ Jarek Kobiela $^{3} \cdot$ Wojciech Makarewicz ${ }^{4} \cdot$ Marek Guzek $^{5} \cdot$ Zbigniew Kmieć $^{1}$
}

Received: 4 August 2018 / Accepted: 29 January 2019 / Published online: 20 February 2019

(c) The Author(s) 2019

\begin{abstract}
Background Tumor necrosis factor superfamily member 15 (TNFSF15) gene is involved in development of several cancers. It encodes two proteins: tumor necrosis factor ligand-related molecule 1A (TL1A) and vascular endothelial growth inhibitor 192 (VEGI-192). The main receptor for TL1A is death receptor 3 (DR3).

Aims We investigated expression of TL1A, VEGI-192, and DR3 transcripts in different stages of colon cancer and compared them with survival of patients. We also aimed to reveal possible effects of microsatellite instability (MSI) and selected TNFSF 15 single-nucleotide polymorphisms (SNPs) on expression of this gene.

Methods Forty-five healthy individuals and 95 colon cancer patients were included in the study. Expression of VEGI-192, $T L 1 A$, and DR3 was measured by quantitative PCR. SNP and MSI analyses were performed on DNA isolated from normal or cancer tissue.

Results Expression of VEGI-192 and TL1A was elevated in colon cancer, although the level of VEGI-192 decreased, while the level of TL1A increased with the progression of cancer. Patients with low expression of TL1A and/or high expression of VEGI-192 in tumor-transformed tissue showed longer survival. DR3 expression was decreased in the cancer, but it did not change with the tumor progression. Alleles T of rs6478108 and G of rs6478109 SNPs were associated with elevated expression of the TNFSF15 gene. There was no relation between the MSI status and TNFSF15 expression levels.

Conclusions Expression of the TNFSF 15 gene isoforms was associated with the progression of colon cancer. Levels of TL1A and VEGI-192 transcripts can be considered as independent prognostic factors for colon cancer.
\end{abstract}

Keywords TNFSF15 · TL1A · VEGI-192 · Colon cancer · Advanced gastric cancer

Tomasz Jerzy Ślebioda

t.slebioda@gumed.edu.pl

Marcin Stanisławowski

m.stanislawowski@gumed.edu.pl

Marta Cyman

marta.cyman@gumed.edu.pl

Piotr Mieczysław Wierzbicki

pwierzb@gumed.edu.pl

Dorota Żurawa-Janicka

dorota.zurawa@biol.ug.edu.pl

Jarek Kobiela

jaroslaw.kobiela@gumed.edu.pl

Wojciech Makarewicz

wojciech.makarewicz@gumed.edu.pl

Marek Guzek

marek.guzek@gumed.edu.pl
Zbigniew Kmieć

zkmiec@gumed.edu.pl

1 Department of Histology, Medical University of Gdańsk, Dębinki 1, 80-211 Gdańsk, Poland

2 Department of Medical and General Biochemistry, University of Gdańsk, Wita Stwosza 59, 80-308 Gdańsk, Poland

3 Department of General, Endocrine and Transplant Surgery, Medical University of Gdańsk, Mariana Smoluchowskiego 17, 80-001 Gdańsk, Poland

4 Department of Oncological Surgery, Medical University of Gdańsk, Mariana Smoluchowskiego 17, 80-001 Gdańsk, Poland

5 Department of Gastroenterology and Hepatology, Medical University of Gdańsk, Mariana Smoluchowskiego 17, 80-001 Gdańsk, Poland 


\section{Introduction}

Colon cancer is currently the third most commonly diagnosed malignancy and the fourth leading cause of cancerrelated deaths in the world. The global burden of colon cancer is expected to increase by $60 \%$ to more than 2.2 million new cases and 1.1 million deaths in 2030 [1]. Development of colon cancer is a sequential process which on average takes around ten years and involves progression from small polyps through adenoma to carcinoma [2].

One of the genes which appears to be involved in colon cancer pathogenesis is TNFSF15. In humans, three different protein isoforms generated from the TNFSF 15 gene were identified-VEGI-174 (174 amino acids), VEGI192 (192 amino acids), and the full-length product VEGI251 (251 amino acids, also known as TL1A), although VEGI-174 is most probably a cloning artifact [3-5]. The main receptor for TL1A is death receptor 3 (DR3, TNFRFSF25), a death domain-containing member of the tumor necrosis factor receptor superfamily [3]. Expression of DR3 is present mostly on activated lymphocytes [6], although it has been detected also in human colon epithelium [7]. In humans, there are 11 splice variants of DR3, out of which the transcript variant 1 encodes the full-length transmembrane product that contains the death domain [6]. Studies by Migone et al. [3] and Metheny-Barlow et al. [4] suggest that VEGI-192 may utilize different receptor(s) or signaling pathways than TL1A and at least some effects of VEGI-192 may be induced independently of DR3 signaling. TL1A is a transmembrane or soluble pro-inflammatory molecule which co-stimulates proliferation and effector functions of $\mathrm{T}$ cells in the presence of TCR stimulation $[6,8]$. Expression of TL1A is localized mostly to activated cells of the immune system-DCs, macrophages, T cells, whereas very little TL1A is present on non-activated immune cells [6]. VEGI-192 on the other hand is expressed mostly on endothelial cells, and its primary function is to inhibit angiogenesis via induction of apoptosis or growth arrest of endotheliocytes [9] or inhibition of endothelial progenitor cells differentiation [10]. Overexpression of VEGI-192 was shown to inhibit tumor neovascularization and progression in a mouse model of lung cancer [11]. In human cancers, higher expression of VEGI-192 mRNA was found in early stages of clear-cell renal cell carcinoma (ccRCC) than in advanced stages of ccRCC. Furthermore, VEGI-192 mRNA levels were negatively correlated with tumor histological differentiation grade [12] and epithelial-mesenchymal transition in renal tumor [13]. In human pituitary tumors, high levels of VEGI-192 mRNA were associated with lower tumor grade and invading pituitary tumors were characterized by lower VEGI-192 mRNA expression [14]. Currently, little is known about the expression pattern and exact function of TL1A in cancer, although mouse studies showed that ectopic expression of TL1A on tumor cells promotes tumor elimination in a CD8(+) T cell-dependent manner [15]. There is, however, a clear association between enhanced TL1A expression and development of certain autoimmune diseases such as psoriasis or inflammatory bowel disease (IBD) [6], and certain TNFSF 15 single-nucleotide polymorphisms are considered as gastric adenocarcinoma [16], IBD [17, 18], and psoriasis [19] risk factors.

Genetic diversity in colon cancers results from, among other factors, uneven replication of noncoding DNA regions, known as microsatellite instability (MSI) which is caused by defects in the DNA mismatch repair (MMR) system. MSI results in increased susceptibility to additional mutations [20] and may affect expression levels or activity of various genes [21].

Currently, there are no published studies on the expression and function of the TNFSF15 gene in human colon cancer and despite the current state of knowledge, the exact molecular mechanism of colon cancer still remains unknown. Its precise characterization might lead to development of new, effective therapies. Therefore, in this study we investigated expression patterns of TL1A, VEGI-192, and $D R 3$ transcripts in tumor-transformed colon mucosa of patients with different stages of colon cancer and compared it with patients' outcome to determine whether these transcripts can be considered as prognostic factors for colon cancer and to gain a better insight into the role of TNFSF15 isoforms in this malignancy. Our study also aimed to reveal the effects of microsatellite instability and selected TNFSF 15 single-nucleotide polymorphisms (rs6478108 and rs6478109) on expression levels of this gene.

\section{Methods}

\section{Patients}

A total of 45 control subjects and 95 colon cancer patients were included in the study. Clinical characteristics of subjects included in the study are presented in Table 1. Tissue samples were collected in years 2014-2016. The control group included healthy participants who underwent screening colonoscopy, showed normal colonic mucosa, and had no history of inflammatory bowel diseases or bowel cancer. The control subjects were not treated with any anti-inflammatory or immunostimulatory drugs and were diagnosed at the Department of Gastroenterology and Hepatology (Medical University of Gdańsk, Poland). Colon mucosa biopsies were collected during routine, diagnostic, or surveillance colonoscopy. Colon cancer patients were diagnosed and treated in the Department of 
Table 1 Clinical characteristics of patients included in the study

\begin{tabular}{lll}
\hline & Colon cancer patients & Control subjects \\
\hline Total number $(n)$ & 95 & 45 \\
Sex $(n)$ & $\mathrm{F}(34) / \mathrm{M}(61)$ & $\mathrm{F}(23) / \mathrm{M}(22)$ \\
Age (years $\pm \mathrm{SD})$ & $61 \pm 10.75$ & $52 \pm 11.8$ \\
Clinical stage & & \\
I & 35 & N/A \\
II & 21 & N/A \\
III & 20 & N/A \\
IV & 19 & N/A \\
Metastases to regional & & \\
lymph nodes & & \\
Absent $\left(\mathrm{N} 0^{\mathrm{a}}\right)$ & 54 & N/A \\
Present $\left(\mathrm{N} 1\right.$ and $\left.\mathrm{N} 2^{\mathrm{a}}\right)$ & 41 & N/A \\
Distant metastases & & \\
Absent $\left(M 0^{\mathrm{a}}\right)$ & 76 & N/A \\
Present $\left(\mathrm{M} 1^{\mathrm{a}}\right)$ & 19 & N/A \\
\hline
\end{tabular}

a According to the TNM classification

N/A not applicable

General, Endocrine and Transplant Surgery (Medical University of Gdańsk, Poland). Cancer tissue samples were collected during routine surgery, and all cases of colon cancer were confirmed by histopathological examination. The patients were not treated with radiotherapy and/or chemotherapy before the surgery and did not receive any anti-inflammatory or immunostimulatory drugs before the surgery. After the surgery, adjuvant therapy was used in 29 patients. This group involves 26 patients with stage III and IV. (The remaining 13 patients refused adjuvant chemotherapy or were disqualified for comorbidities or poor general performance status.) Three patients with clinical stage II received the adjuvant chemotherapy because of significant risk factors. Chemotherapy regimens were applied according to EURECCA guidelines used in our institution [22].

\section{RNA Isolation and Reverse Transcription}

Colon mucosa biopsies and colon cancer samples were immersed in RNA Later fluid (Sigma-Aldrich, Munich, Germany) and stored at $-80{ }^{\circ} \mathrm{C}$ until RNA isolation. Total RNA was extracted with RNA Mini Kit (A\&A Biotechnology, Gdynia, Poland) according to the manufacturer's instructions. The extracted RNA was treated with TURBO DNAfree Kit (Ambion, Austin, TX, USA) to remove any possible contamination with genomic DNA. RNA concentration and $260 \mathrm{~nm} / 280 \mathrm{~nm}$ absorbance ratio (average 1.95, range 1.90-2.02) were determined using Epoch spectrophotometer (BioTek, Potton, UK). RNA integrity (RIN) was assessed with Bioanalyzer 2100 (Agilent Technologies, Palo Alto, CA, USA). The average RIN value was 7.2 (range 5.1-9.4). Reverse transcription of $1 \mu \mathrm{g}$ of total RNA extracted from each sample was carried out with RevertAid First-Strand cDNA Synthesis Kit (Thermo Scientific, Fitchburg, WI, USA) according to the manufacturer's instructions. The obtained cDNA was stored at $-25{ }^{\circ} \mathrm{C}$ until further analyses.

\section{Quantitative PCR}

The primers used for quantitative PCR (qPCR) were designed and evaluated using NCBI database and PrimerBLAST software. To amplify cDNA target only and to avoid amplification of any possible genomic DNA contamination, we chose primers that span exon/exon junctions or primer pairs that were separated by at least one intron of more than $1000 \mathrm{bp}$ size on the corresponding genomic DNA. Sequences of the primers, annealing temperatures, efficiency values of qPCR assays, and RefSeq accession numbers are presented in Table 2 [23]. qPCR reactions were performed in StepOnePlus instrument (Life Technologies, Grand Island,

Table 2 Sequences of primers used in the study

\begin{tabular}{|c|c|c|c|c|c|}
\hline Gene (isoform) & Forward primer & Reverse primer & $\begin{array}{l}\text { Annealing } \\
\text { temperature } \\
\left({ }^{\circ} \mathrm{C}\right)\end{array}$ & $\begin{array}{l}\text { qPCR } \\
\text { efficiency } \\
(\%)\end{array}$ & RefSeq accession number \\
\hline IPO8 & $\begin{array}{l}\text { 5'-TTGGAAGAAACCGCG } \\
\text { CTTGAGG-3' }\end{array}$ & $\begin{array}{l}\text { 5'-ACCAGGCTGCATCTC } \\
\text { GACTCTG-3' }\end{array}$ & 59 & 98.75 & NM_001190995 \\
\hline PPIA & $\begin{array}{l}\text { 5'-CTTGGGCCGCGTCTC } \\
\text { CTTTGAG-3' }\end{array}$ & $\begin{array}{l}\text { 5'-GCTTGCCATCCAACC } \\
\text { ACTCAGTC-3' }\end{array}$ & 59 & 97.25 & NM_001300981.1 \\
\hline TNFSF15 (TL1A) & $\begin{array}{l}\text { 5'-AAGGACAGGAGTTTG } \\
\text { CACCTTCA-3' }\end{array}$ & $\begin{array}{l}\text { 5'-AAGTGCTGTGTGGGA } \\
\text { GTTTGTCT-3' }\end{array}$ & 62 & 98.56 & NM_005118.3 \\
\hline TNFSF15 (VEGI-192) & $\begin{array}{l}\text { 5'-AAGGGCCGTCTTCAT } \\
\text { TTCAGT-3' }\end{array}$ & $\begin{array}{l}\text { 5'-TCGGCCTGCTTGTCT } \\
\text { GATTT-3' }\end{array}$ & 60 & 97.25 & NM_001204344.1 \\
\hline $\begin{array}{l}\text { TNFRSF25 (transcript } \\
\text { variant 1) [23] }\end{array}$ & $\begin{array}{l}\text { 5'-ATGGCGATGGCTGCG } \\
\text { TGTCCTG-3' }\end{array}$ & $\begin{array}{l}\text { 5'-AGCGCCTCCTGGGTC } \\
\text { TCGGGGTAG-3' }\end{array}$ & 63 & 94.23 & NM_148965.1 \\
\hline
\end{tabular}


NY, USA). Each reaction mixture contained $1 \mu \mathrm{L}$ of undiluted cDNA, $0.2 \mu \mathrm{M}$ of forward and reverse primers, $10 \mu \mathrm{L}$ of SensiFast No-Rox Kit (Bioline, London, UK; containing Sybr ${ }^{\circledR}$ Green fluorophore, Taq DNA polymerase, and a mixture of deoxynucleotides), and water to $20 \mu \mathrm{L}$. Conditions of qPCR reactions were as follows: denaturation for $2 \mathrm{~min}$ at $95{ }^{\circ} \mathrm{C}$ followed by 40 cycles of denaturation for $5 \mathrm{~s}$ at $95^{\circ} \mathrm{C}$, annealing for $10 \mathrm{~s}$ at $59-63{ }^{\circ} \mathrm{C}$, and an extension step (with fluorescence reading) for $20 \mathrm{~s}$ at $72{ }^{\circ} \mathrm{C}$. The presence of a single, specific PCR product in each reaction was confirmed by melting curve analysis. All qPCR reactions were performed in triplicates, and the geometric means of $\mathrm{Ct}$ values were used for data analysis. Gene expression data were normalized to mean expression levels of PPIA and IPO8 genes which showed the highest stability in the tested biological samples among other evaluated housekeeping genes, including HPRT1, GAPDH, RPLPO, beta-2-microglobulin, and beta-actin (own data).

\section{Single-Nucleotide Polymorphism Analysis}

Genomic DNA from normal colon tissue collected from colon cancer patients during tumor resection was extracted using Extractme ${ }^{\circledR}$ DNA Tissue Kit (Blirt, Gdańsk, Poland) in accordance with the manufacturer's instructions. Singlenucleotide polymorphism (SNP) genotyping was carried out with TaqMan allelic discrimination assay from Applied Biosystems (Foster City, CA, USA). The SNP assays were also purchased from Applied Biosystems. Every reaction in a 96-well plate was conducted in the total volume of $25 \mu \mathrm{L}$ per well, including $11.25 \mu \mathrm{L}$ purified genomic DNA sample with DNase-free water $(15 \mathrm{ng} / \mu \mathrm{L}$ extracted DNA per well), $12.5 \mu \mathrm{L}$ TaqMan Universal PCR Master Mix (2×), and $1.25 \mu \mathrm{L}$ SNP Genotyping Assay (20x). All of the samples were analyzed in duplicates. A negative control was included in each assay. The amplification protocol consisted of $10 \mathrm{~min}$ at $95^{\circ} \mathrm{C}$ and 40 cycles of amplification $\left(95^{\circ} \mathrm{C}\right.$ for $15 \mathrm{~s}$ and $60^{\circ} \mathrm{C}$ for $60 \mathrm{~s}$ ). All TaqMan real-time PCR runs were performed using the StepOnePlus ${ }^{\mathrm{TM}}$ Real-Time PCR System (Applied Biosystems, Foster City, CA, USA) with the StepOne ${ }^{\mathrm{TM}}$ Software v 2.2.2.

\section{Microsatellite Instability Analysis}

Microsatellite instability (MSI) status was determined according to the National Cancer Institute Workshop and Familial Predispositions and was based on polymorphism analysis of five markers: BAT26 and D2S123 for MSH2, BAT25 for the c-kit oncogene, APC-D5S346 for APC gene, and MFd15 D17S250 for BRCA1 gene [24]. MSI status was assessed with the use of high-resolution melting qPCR according to [25] with certain modifications. The referenced [26] primers were purchased from Sigma-Aldrich (Sigma-Aldrich, Munich,
Germany). DNA of $15 \mathrm{ng}$ extracted from paired tumor and normal colon was used for PCR amplification with SensiFast HRM (BioLine, London, UK) and $200 \mathrm{nM}$ each primer in the final volume of $10 \mu \mathrm{l}$. All reactions were run in duplicates. First, the reactions were run in qPCR 8-tube stripes (4titude, Wotton, UK) in MyGo Pro Real-Time PCR System (IT-IS International Ltd., Stokesley, UK) at the following conditions: $95{ }^{\circ} \mathrm{C}$ for $3 \mathrm{~min}, 35$ cycles of $95^{\circ} \mathrm{C}$ for $10 \mathrm{~s}, 51^{\circ} \mathrm{C}$ for $10 \mathrm{~s}$ and $72{ }^{\circ} \mathrm{C}$ for $15 \mathrm{~s}$ (fluorescence reading). HRM profile: from $60{ }^{\circ} \mathrm{C}$ to $97^{\circ} \mathrm{C}$ with fluorescence reading every $0.05^{\circ} \mathrm{C}$. MSI pattern was assessed by auto high-resolution melt with the use of MyGo Pro PCR Software ver. 3.3 (IT-IS International). Furthermore, HRM analysis was duplicated (by transferring the PCR stripes with PCR products) at StepOnePlus apparatus (Life Technologies-Applied Biosystems, Grand Island, $\mathrm{NY}$, USA) with the following profile: from 60 to $95^{\circ} \mathrm{C}$ with fluorescence reading every $0.2^{\circ} \mathrm{C}$. HRM analysis at StepOnePlus apparatus was assessed by high-resolution Melting software ver. 3.0 (Life Technologies_-Applied Biosystems) using manual of auto alignment of melt curves. The occurrence of microsatellite instability was noted if the additional melting spike appeared in tumor samples. If the results of analyses at MyGo and StepOnePlus were different, the PCR reaction was repeated. If the MSI occurred at 1-2 markers, low-grade MSI (MSI-L) was noted; if the mutation was observed at 2-5 markers, high-grade MSI (MSI-H) was acknowledged.

\section{Data Analysis}

For relative gene expression, $\mathrm{Ct}$ values of the tested genes were first normalized to mean $\mathrm{Ct}$ values of reference genes (IPO8 and PPIA) $(\triangle \mathrm{Ct})$ and $2^{-\Delta \mathrm{Ct}}$ values of individual patients in colon cancer groups were then normalized to the average $2^{-\Delta \mathrm{Ct}}$ value in control patients. Multivariate analysis was performed with Cox proportional hazards regression model. All statistical calculations were performed with Prism 6 software (GraphPad, San Diego, CA, USA) or XLSTAT (Addinsoft, New York, USA). Normality of gene expression data was checked with D'Agostino and Pearson omnibus test and Mann-Whitney U test, Friedman's ANOVA with Bonferroni post hoc test or log-rank (Mantel-Cox) test were used to compare gene expression data. $\mathrm{P}$ values lower or equal to 0.05 were considered as statistically significant.

\section{Results}

\section{TL1A and VEGI-192 but Not DR3 mRNA Expression Levels Change with the Progression of Colon Cancer}

To investigate the expression pattern of TL1A, VEGI-192, and $D R 3$ in colon cancer, we measured the levels of their 
transcripts in tumor-transformed colon mucosa and normal colon mucosa collected from healthy subjects. Initial analysis of gene expression showed that levels of TL1A and VEGI192 transcripts were significantly elevated in tumor-transformed tissue as compared to control samples (on average 6.54-fold and 54.99-fold, respectively; Fig. 1). Interestingly, the level of $D R 3$ transcript variant 1 was slightly but significantly lower in cancer tissue than in control colon mucosa (on average 0.70 -fold; Fig. 1). Further analysis of gene expression data revealed that expression of TL1A mRNA increased with the progression of colon cancer. Compared to healthy control tissue, in colon cancer the level of TL1A transcript was on average 3.54-fold higher in stage I, 3.97-fold higher in stage II, 5.85-fold higher in stage III, and 11.21fold higher in stage IV (Fig. 2a). Moreover, TL1A mRNA levels were significantly elevated in tumors that metastasized to regional lymph nodes (on average 2.22-fold higher than in tumors without metastases to regional lymph nodes; Fig. 2b) and formed distant metastases (on average 2.79-fold higher than in tumors without distant metastases; Fig. 2c). An opposite expression pattern of VEGI-192 mRNA was observed in colon cancer tissue. Even though overall expression of VEGI-192 transcript was higher in tumor-transformed tissue than in healthy colon mucosa, its expression decreased with the progression of colon cancer. Compared to healthy tissue, the level of VEGI-192 transcript was on average 86.26-fold higher in stage I, 33.36-fold higher in stage II, 16.79-fold higher in stage III, and 14.17-fold higher in stage IV colon cancer (Fig. 2a). The expression of VEGI-192 mRNA was significantly lower in tumors that formed metastases to regional lymph nodes (on average 0.22 -fold; Fig. 2b) and distant metastases (on average 0.24-fold; Fig. 2c) than in tumors that did not form any metastases. Interestingly, expression of $D R 3$ transcript variant 1 did not change with the progression of colon cancer (Fig. 2a-c).

\section{Expression Levels of TL1A and VEGI-192 mRNA Are Associated with Single-Nucleotide Polymorphisms rs6478108 and rs6478109}

Our study showed that colon cancer patients with $\mathrm{C} / \mathrm{T}$ and $\mathrm{T} / \mathrm{T}$ genotypes of rs 6478108 have higher expression of TL1A transcript than colon cancers with $\mathrm{C} / \mathrm{C}$ genotype of rs6478108 (2.65-fold and 3.20-fold, respectively). Expression of VEGI-192 transcript was 1.83-fold higher in colon cancer samples with T/T rs6478108 genotype as compared to $\mathrm{C} / \mathrm{T}$ genotype, although we did not find any differences between samples with other genotypes (Fig. 3a). Also, colon cancers with $\mathrm{A} / \mathrm{G}$ and $\mathrm{G} / \mathrm{G}$ genotypes of rs6478109 had higher expression of TL1A mRNA than colon cancers with genotype A/A of the same SNP (2.72-fold and 3.01fold, respectively). Colon cancers with genotype G/G of rs6478109 had 1.96-fold higher expression of VEGI-192 transcript as compared to A/G genotype, and there were no significant differences in VEGI-192 mRNA expression between other genotypes (Fig. 3b).

\section{Microsatellite Instability Does Not Affect Levels of TL1A and VEGI-192 mRNA Expression in Patients with Colon Cancer}

Since dysfunction of the DNA mismatch repair (MMR) system, leading to microsatellite instability (MSI), may result in altered expression levels of certain genes, such as $B A X, F A S$, and others [21], we decided to check whether MSI status can be associated with expression levels of the two isoforms of the TNFSF 15 gene. However, having compiled VEGI192 and TL1A mRNA expression data with the MSI status of the investigated patients, we did not find any correlation between the MSI status and expression levels of VEGI-192 and TLIA transcripts (Fig. 4).
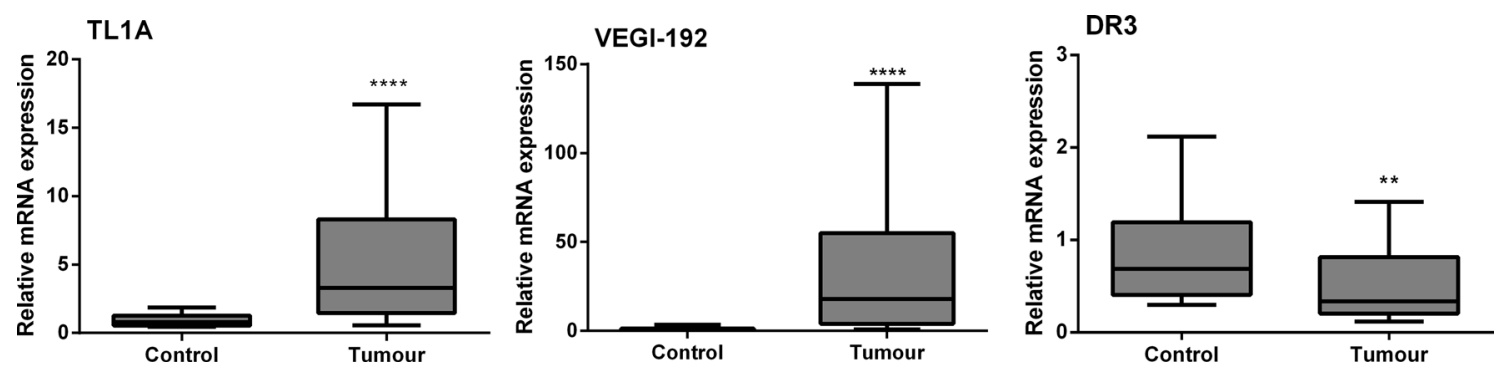

Fig. 1 Relative expression of TL1A, VEGI-192, and DR3 mRNA in colon cancer tissue. The data are presented as a fold change versus the mean value in the control healthy colon mucosa. ${ }^{* *} p=0.005$;
**** $p<0.0001 . p$ values were calculated with Mann-Whitney $U$ test. Box and whisker plots represent median values and 5-95 percentiles 

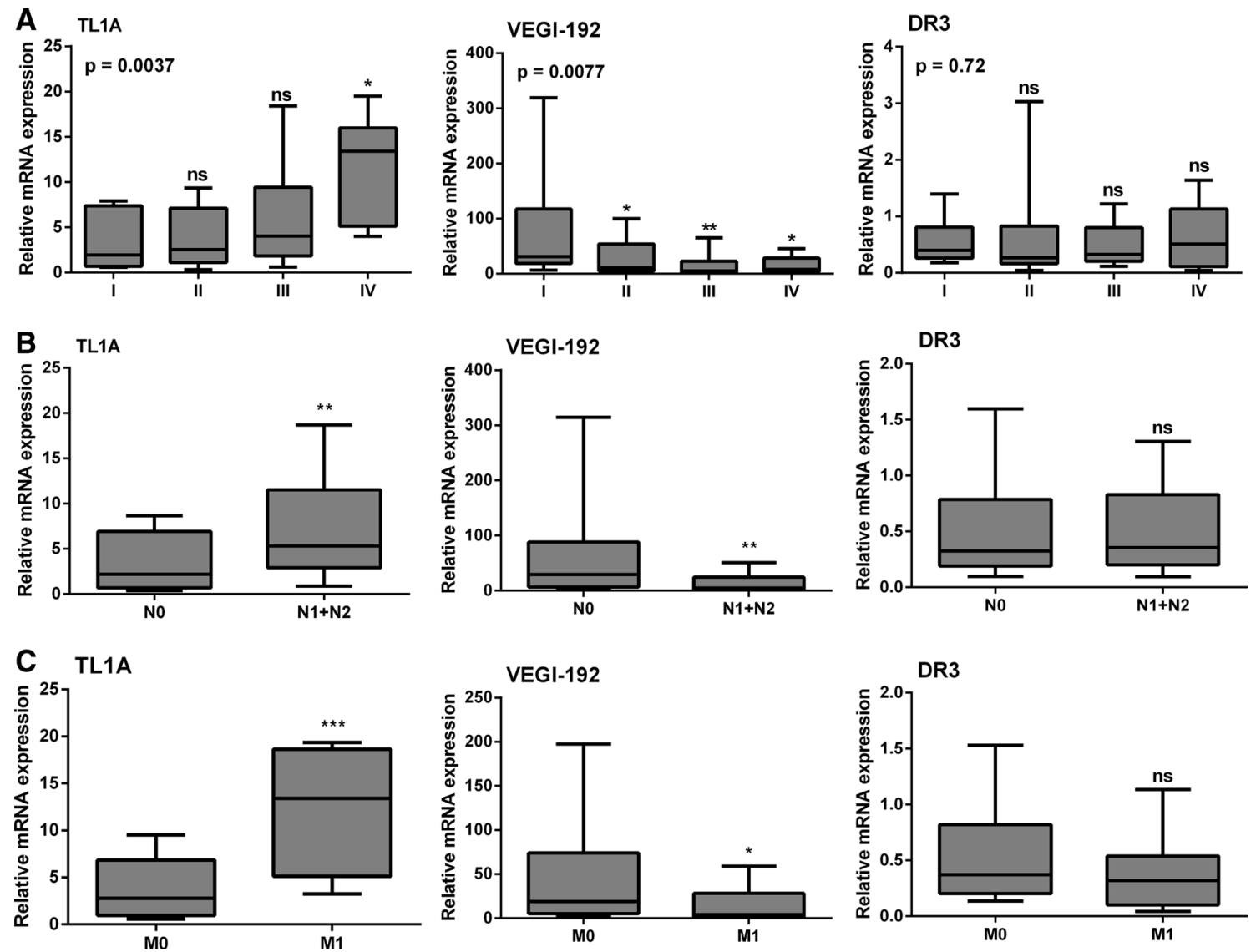

Fig. 2 Relative expression of TL1A, VEGI-192, and DR3 mRNA in different stages of colon cancer $(\mathbf{a})$; in cancers with $(\mathrm{N} 1+\mathrm{N} 2)$ or without (N0) metastases to regional lymph nodes (b); and in cancer with (M1) or without (M0) distant metastases (c). The data are presented as a fold change versus the mean value in the control healthy colon mucosa. $* p=0.01 ; \quad * * 0.003>p>0.001 ; \quad * * * p=0.0001$;

\section{Expression Levels of TL1A, VEGI-192, and DR3 mRNA Are Associated with Different Survival of Colon Cancer Patients}

To investigate whether expression levels of TL1A, VEGI192 , and $D R 3$ transcripts have any relationship with survival of colon cancer patients, we grouped them as "high" and "low" depending on the mean expression value of a given transcript. Survival of the patients was monitored for 30 months. Patients with TL1A mRNA expression lower or equal to 6.54-fold increase over healthy controls ("low"; $n=62$ ) showed higher survival rate than patients with high TL1A mRNA expression $(n=33)$. Patients with $D R 3$ mRNA expression lower or equal to 0.70 -fold decrease under healthy controls ("low"; $n=60$ ), and patients with VEGI-192 mRNA expression lower or equal to 54.99-fold increase over healthy controls ("low"; $n=69$ ) had lower survival rate than patients with high expression levels of the respective transcripts (DR3 high: $n=35$; VEGI-192
${ }^{\mathrm{ns}} p \geq 0.05$. $p$ values in (a) presented as alphanumeric values were calculated with Friedman's ANOVA with Bonferroni post hoc test; $p$ values in (a) presented as symbols were calculated with Mann-Whitney $U$ test versus group I. In $(\mathbf{b}, \mathbf{c}), p$ values were calculated with Mann-Whitney $U$ test. Box and whisker plots represent median values and 5-95 percentiles

high: $n=26$ ) (Fig. 5). In the next step, we chose patients with both low expression of TL1A and high expression of VEGI-192 mRNA in tumor tissue $(n=13)$ and compared their survival rate with patients with both high expression of TL1A and low expression of VEGI-192 mRNA in tumor tissue $(n=21)$. The survival rate of the colon cancer patients with both low TL1A and high VEGI-192 mRNA expression was significantly higher than of patients with both high TLIA and low VEGI-192 mRNA expression (Fig. 5). Interestingly, we did not find any differences in survival rates of colon cancer patients with low TL1A, high VEGI-192, and high DR3 mRNA expression $(n=4)$ and the patients with high TL1A, low VEGI-192, and low DR3 mRNA expression ( $n=16)$ (Fig. 5). Multivariate analysis, which included patients receiving and not receiving adjuvant therapy after the surgery, revealed that high expression of TL1A and low expression of VEGI-192, but not expression level of DR3, were independent risk factors in the investigated patients (Table 3). 
Fig. 3 Relative expression of TL1A and VEGI-192 mRNA in patients with different genotypes of rs6478108 (a) or rs6478109 (b) single-nucleotide polymorphisms. The data are presented as a fold change versus the mean value in the control healthy colon mucosa. $p$ values were calculated with Mann-Whitney $U$ test. Box and whisker plots represent median values and 5-95 percentiles
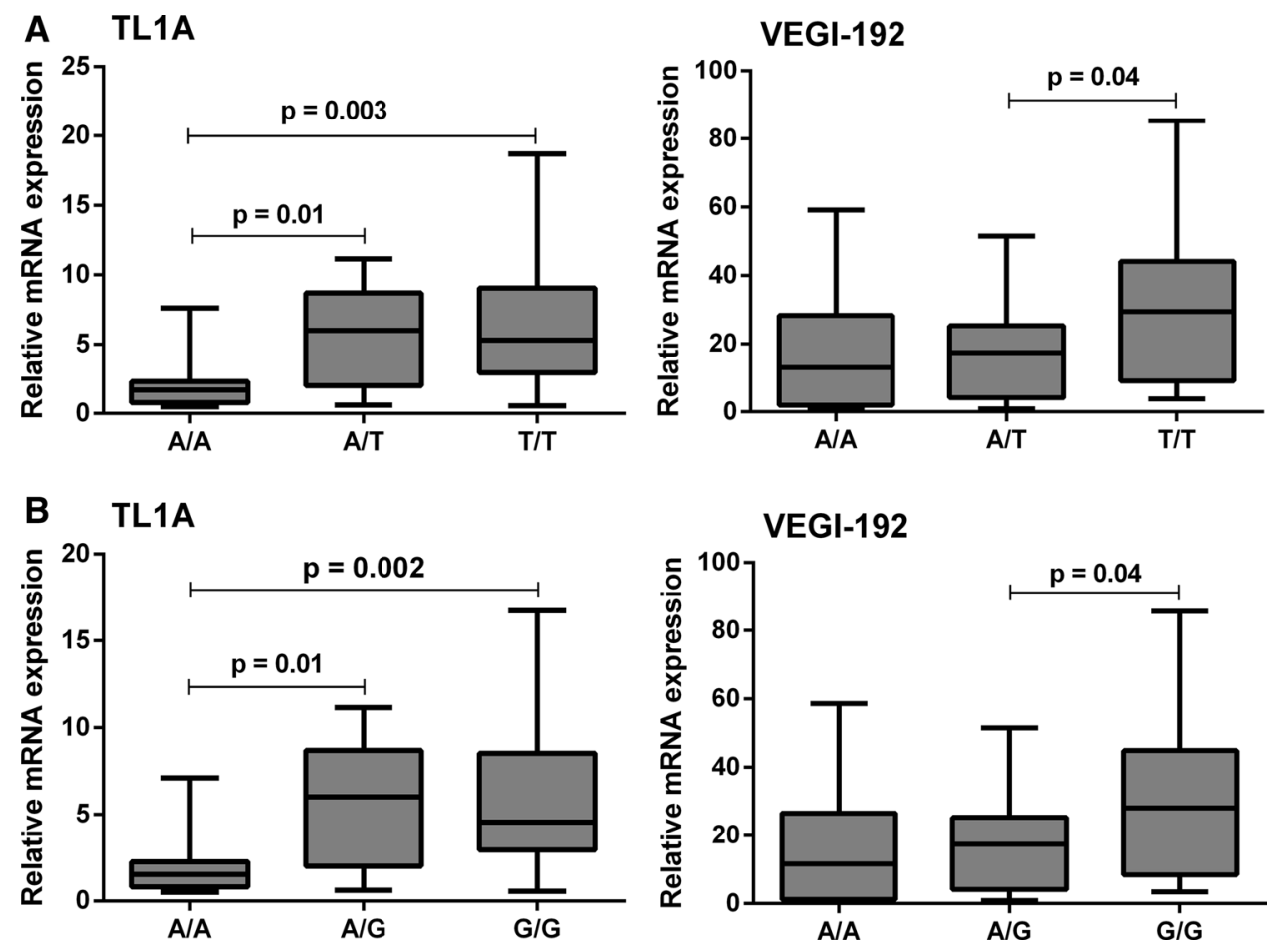

TL1A

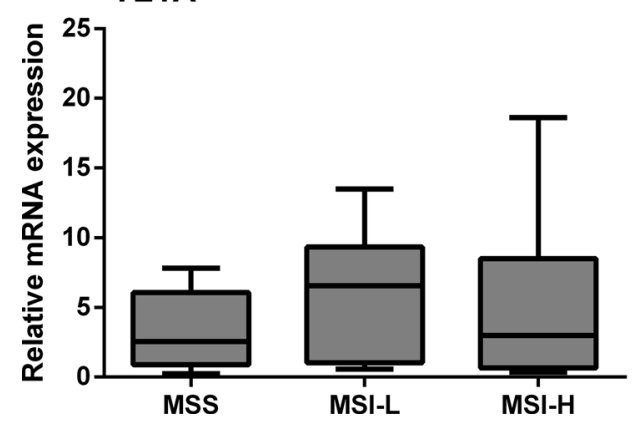

Fig. 4 Relative expression of TL1A and VEGI-192 mRNA in patients with stable microsatellites (MSS), low-grade microsatellite instability (MSI-L), or high-grade microsatellite instability (MSI-H) in colon cancer tissue. The data are presented as a fold change versus the mean

\section{Discussion}

Most of the previous studies on expression of the TNFSF 15 gene in human and animal malignancies did not differentiate between VEGI-192 and TL1A isoforms, and did not specify precisely enough which isoform was detected or focused on total expression of the TNFSF15 gene. Therefore, it is difficult to compare the results obtained by our group with the studies of other researchers. This study is, to our best knowledge, the first one that reports that VEGI192 and TL1A transcripts have distinct expression patterns in human colon cancer and that their levels in tumor tissue are associated with tumor invasiveness. Expression

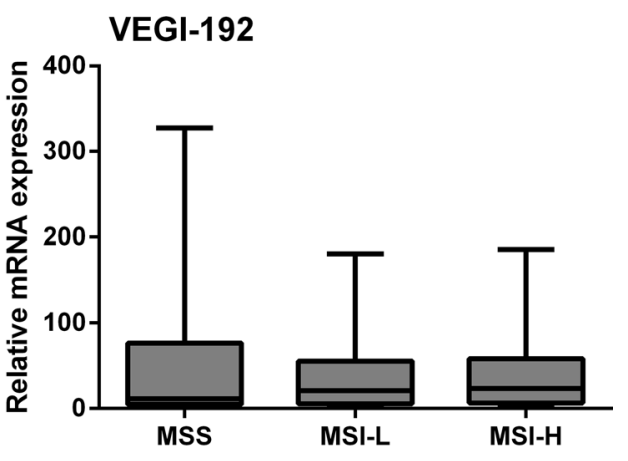

value in the control healthy colon mucosa. Comparison of groups did not show any statistically significant differences $(p \geq 0.05) . p$ values were calculated with Mann-Whitney $U$ test. Box and whisker plots represent median values and 5-95 percentiles

levels of both TLIA and VEGI-192 transcripts were significantly elevated in colon cancer tissue as compared to healthy colon mucosa; however, high TL1A mRNA expression seems to be linked to progression and invasiveness of colon cancer, whereas VEGI-192 mRNA expression pattern is opposite. Moreover, colon cancer patients with low expression of TL1A and/or high expression of VEGI192 mRNA in tumor tissue showed longer survival. In our study, RNA was isolated from either colon mucosa (control subjects) or whole colon cancer mass (tumor patients). Therefore, it is difficult to determine exactly which cells were producers of TL1A, VEGI-192, and/or DR3, since the investigated tumor tissue fragments contained not only 

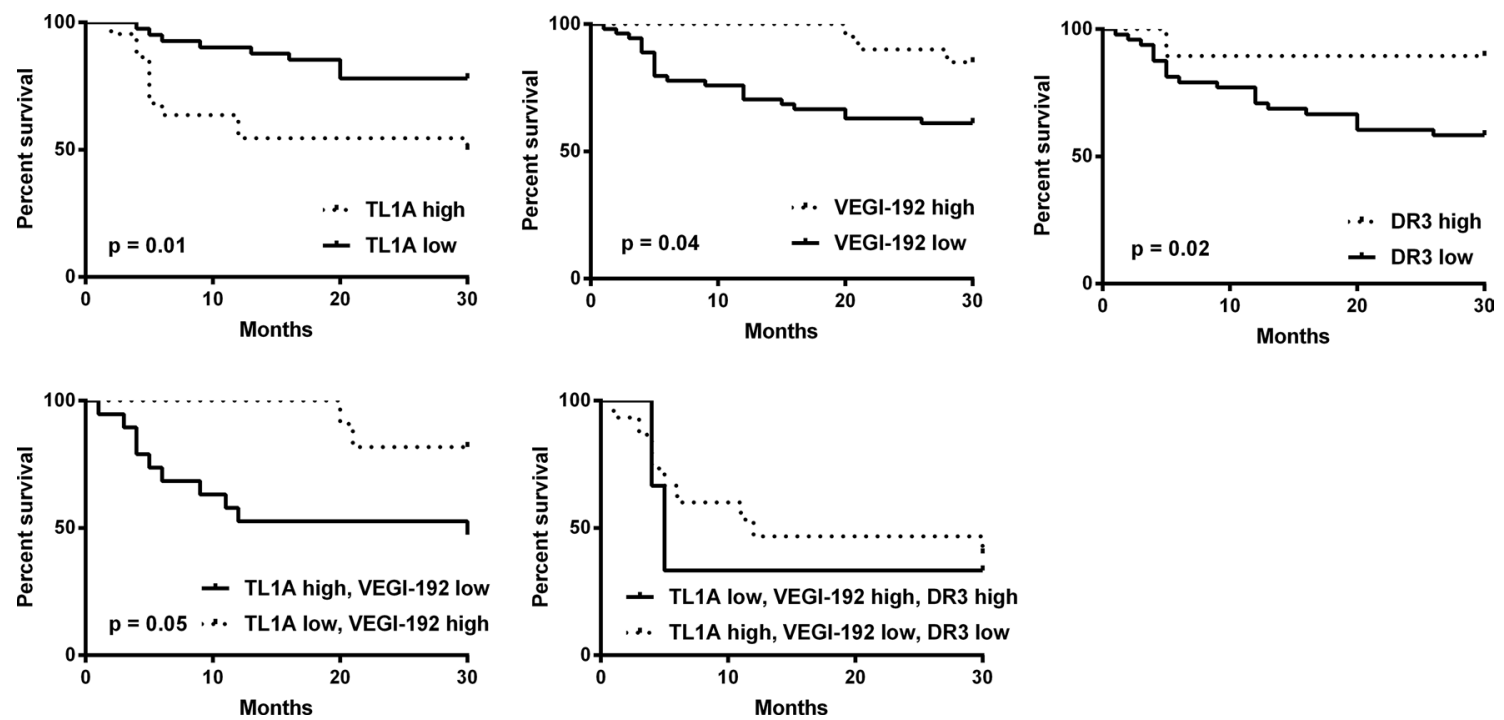

Fig. 5 Survival curves of patients with high and/or low expression of TL1A, VEGI-192, and DR3 mRNA. If no $p$ values are presented on a graph, $p \geq 0.05$. $p$ values were calculated with log-rank (Mantel-Cox) test

Table 3 Identification of independent prognostic factors by Cox multivariate analysis

\begin{tabular}{lll}
\hline Variable & HR (95\% CI $)$ & $p$ \\
\hline Age & $1.060(1.020-1.102)$ & 0.003 \\
Stage & $2.037(0.640-6.487)$ & 0.229 \\
N stage (N1+ N2 vs. N0) & $0.549(0.123-2.451)$ & 0.432 \\
M stage (M1 vs. M0) & $4.159(0.901-19.201)$ & 0.068 \\
TL1A expression (low vs. high) & $0.420(0.000-0.966)$ & 0.041 \\
VEGI-192 expression (low vs. high) & $2.374(1.081-5.215)$ & 0.031 \\
DR3 expression (low vs. high) & $0.647(0.279-1.498)$ & 0.309 \\
Adjuvant therapy (present vs. absent) & $0.472(0.171-1.301)$ & 0.148 \\
\hline
\end{tabular}

cancer cells but also cells of tumor stroma and infiltrating mononuclear cells of the immune system.

Our findings stand in agreement with studies conducted by Zhang et al. [12] who showed that levels of VEGI-192 mRNA were higher in clear-cell renal cell carcinoma of earlier stages than in cancers of advanced stages. Interestingly, in the cited study [12] expression of TL1A transcript in cancer tissue samples was similar and that of VEGI-192 transcript was lower than in normal tissue. This discrepancy is difficult to explain since the laboratory technique used by Zhang et al. [12] to measure levels of TLIA and VEGI-192 transcripts (quantitative PCR) was similar to the method used by us and the only difference was the type of tumor. Therefore, we believe that this difference may be tumor dependent. The role of VEGI-192 in tumor progression appears to be associated with its anti-angiogenic function. The growth of solid tumors strictly depends on angiogenesis, and several studies demonstrated that the degree of tumor vascularity correlates positively with the disease stage and the likelihood of metastases formation [27]. Since VEGI192 is a typical anti-angiogenic molecule [9], its decreased expression in advanced tumors may trigger formation of blood vessels in tumor tissue and in this way facilitate the progression of the disease.

TL1A, on the other hand, is a pro-inflammatory molecule that interacts with the death receptor 3 (DR3) which results in activation of the transcription factor NF- $\mathrm{kB}$ [28] and can boost anti-tumor immunity by mounting $\mathrm{T}$ cell immunity. Therefore, TL1A shows a high degree of functional similarity with tumor necrosis factor (TNF) signaling via TNF receptor 2 (TNFR2). It is well established that prolonged stimulation with pro-inflammatory molecules contributes to elevated risk of tumor transformation [29]. Indeed, TNF promotes tumor progression via induction of pro-inflammatory cytokines and matrix metalloproteinases [30], and elevated expression of TNF is associated with poor prognosis and cachexia [31]. Several authors suggest that the link between inflammation and cancer is the transcription factor NF- $\mathrm{kB}$ since its pathway promotes tumor growth due to the activation of anti-apoptotic genes in malignant cells and proinflammatory cytokines' expression by myeloid and lymphoid cells which in turn act on epithelial cells promoting their proliferation and survival [29, 32, 33]. Interestingly, inhibition of NF- $\mathrm{KB}$ activity at early stages of tumor did not affect tumor transformation of epithelial cells. Instead, it suppressed tumor growth and progression at advanced stages of cancer development [33]. This finding is supported by studies conducted by Moorchung et al. [34] who showed that in colon cancer, higher nuclear translocation of NF- $\mathrm{kB}$ was detected in lymphocytes infiltrating malignant rather 
than benign tumors. In a recent article, Niu and colleagues showed in a mouse model of colitis-induced colon cancer that TL1A contributes to progression of this disease via activation of $\mathrm{Wnt} / \beta$-catenin pathway [35]. These observations are consistent with our findings that elevated expression of TL1A transcript is associated with the progression of colon cancer in humans. Therefore, we speculate that this cytokine, similarly to TNF, may contribute to colon cancer development by enhancing inflammation in the tumor microenvironment and the balance between its protective and pro-tumorigenic function most probably depends on local concentration and time of stimulation.

At present, the role of DR3 in cancer development and progression still remains unclear. An in vitro study conducted on human colon cancer cell lines HT29 and LoVo showed that DR3 expressed by cancer cells binds to E-selectin present on human umbilical vein endotheliocytes (HUVEC) and acts as a metastasis trigger, allowing cancer cells to evade apoptosis and activate survival and migratory events [36]. Other authors reported that DR3 expression is reduced in hepatocellular carcinoma cell lines [37] and human breast cancer in which it also was associated with worse prognosis [38]. On the contrary, it was found that DR3 expression levels did not correlate with human pituitary tumor invasion [14]. To our best knowledge, expression of $D R 3$ mRNA levels in human colon cancer has not been studied to date. Even though our study showed that $D R 3$ mRNA levels were lower in colon cancer tissue than in control samples and colon cancer patients with high expression of DR3 mRNA in colon cancer tissue showed longer survival rates, we did not find any association between $D R 3$ expression levels and progression of colon cancer. Due to very sparse available literature data concerning expression and role of DR3 in human cancers, currently it is very difficult to unambiguously define its function in cancer development.

There are many known single-nucleotide polymorphisms of the TNFSF15 gene which are associated with inflammatory bowel diseases or certain types of cancer. To our best knowledge, currently there are not any published studies on expression levels of TL1A and VEGI-192 mRNA in colon cancer in relation to TNFSF 15 single-nucleotide polymorphisms. Therefore, we have decided to investigate association of two common TNFSF15 SNPs, rs6478108 and rs6478109, with transcriptional activity of this gene in colon cancer patients. Studies conducted by other authors showed that these SNPs are associated with elevated risk for developing gastric adenocarcinoma [16], ulcerative colitis [18], or Crohn's disease [39, 40]. In this study, we showed that elevated expression of TL1A mRNA is associated with $\mathrm{C} / \mathrm{T}$ and $\mathrm{T} / \mathrm{T}$ genotypes of rs6478108 single-nucleotide polymorphism (SNP) and A/G and G/G genotypes of rs6478109 $\mathrm{SNP}$, while increased expression of VEGI-192 mRNA is associated with T/T genotype of rs6478108 SNP and G/G genotype of rs6478109 SNP. Therefore, we suppose that the alleles responsible for enhanced expression of the TNFSF 15 gene are T for rs6478108 SNP and G for rs6478109 SNP. This finding is consistent with the observations of other authors who showed that allele T of rs6478108 SNP is a risk allele for ulcerative colitis [18], while C/C genotype of rs6478108 SNP and A/A genotype of rs6478109 are protectively associated with Crohn's disease [39]. Moreover, in vitro studies by Hedl and colleagues showed that the allele A of rs6478109 SNP is related to enhanced expression of the TNFSF 15 gene in macrophages [41]. Even though rs6478108 and rs6478109 SNPs are clearly associated with expression levels of the TNFSF 15 gene, it is difficult to speculate at this moment which of the alleles is the risk factor for colon cancer since TL1A and VEGI-192 appear to play opposite roles in the progression of this disease. Our studies suggest also that expression levels of the TNFSF15 gene do not depend on microsatellite instability status of the patients' genome isolated from the tumor-transformed tissue.

During the course of the studies presented in this article, we made an attempt to detect TL1A and VEGI-192 proteins in colon cancer and control tissue by western blotting. However, expression levels of these proteins were close to detection limit of the technique that we used (data not shown); therefore, it was impossible to use the obtained results for quantitative analysis of TL1A and VEGI-192 expression. Also, detection of these proteins in the collected tissues by immunohistochemistry was very problematic due to the lack of commercially available antibodies that unambiguously detect the two isoforms separately. In fact, there are very few published studies that show the presence and clearly distinguish the expression of native TL1A or VEGI-192 proteins in human tissue $[42,43]$ which is most probably caused by low expression of these proteins and technical limitations.

In summary, we show here for the first time that $T L 1 A$ and VEGI-192 transcripts have opposite expression patterns in human colon cancer, related to the progression of this malignancy and survival of colon cancer patients. For these reasons, the levels of TLIA and VEGI-192 transcripts in colon cancer tissue can be considered as prognostic markers for this disease.

Acknowledgments The study was supported by the Polish National Science Centre Grant No. 2013/09/D/NZ5/02653.

\section{Compliance with ethical standards}

Conflict of interest The authors declare no conflicts of interests.

Ethical statement All procedures were performed in studies involving human participants were in accordance with the ethical standards of the institutional and/or national research committee and with the 1964 Declaration of Helsinki and its later amendments or comparable ethical standards. 
Informed consent Informed consent was obtained from all individual participants included in the study.

Open Access This article is distributed under the terms of the Creative Commons Attribution-NonCommercial 4.0 International License (http://creativecommons.org/licenses/by-nc/4.0/), which permits any noncommercial use, distribution, and reproduction in any medium, provided you give appropriate credit to the original author(s) and the source, provide a link to the Creative Commons license, and indicate if changes were made.

\section{References}

1. Arnold M, Sierra MS, Laversanne M, et al. Global patterns and trends in colorectal cancer incidence and mortality. Gut. 2017;66:683-691.

2. Hadjipetrou A, Anyfantakis D, Galanakis CG, Kastanakis M, Kastanakis S. Colorectal cancer, screening and primary care: a mini literature review. World J Gastroenterol. 2017;23:6049-6058.

3. Migone TS, Zhang J, Luo X, et al. TL1A is a TNF-like ligand for DR3 and TR6/DcR3 and functions as a T cell costimulator. Immunity. 2002;16:479-492.

4. Metheny-Barlow LJ, Li LY. Vascular endothelial growth inhibitor (VEGI), an endogenous negative regulator of angiogenesis. Semin Ophthalmol. 2006;21:49-58.

5. Chew LJ, Pan H, Yu J, et al. A novel secreted splice variant of vascular endothelial cell growth inhibitor. FASEB J. 2002;16:742-744.

6. Richard AC, Ferdinand JR, Meylan F, et al. The TNF-family cytokine TL1A: from lymphocyte costimulator to disease coconspirator. J Leukoc Biol. 2015;98:333-345.

7. Slebioda TJ, Bojarska-Junak A, Stanislawowski M, et al. TL1A as a potential local inducer of IL17A expression in colon mucosa of inflammatory bowel disease patients. Scand J Immunol. 2015;82:352-360.

8. Slebioda TJ, Kmiec Z. Tumour necrosis factor superfamily members in the pathogenesis of inflammatory bowel disease. Mediators Inflamm. 2014;2014:325129.

9. Zhang N, Sanders AJ, Ye L, Jiang WG. Vascular endothelial growth inhibitor in human cancer (Review). Int $\mathrm{J} \mathrm{Mol} \mathrm{Med.}$ 2009;24:3-8

10. Tian F, Liang PH, Li LY. Inhibition of endothelial progenitor cell differentiation by VEGI. Blood. 2009;113:5352-5360.

11. Hou W, Medynski D, Wu S, Lin X, Li LY. VEGI-192, a new isoform of TNFSF15, specifically eliminates tumor vascular endothelial cells and suppresses tumor growth. Clin Cancer Res. 2005;11:5595-5602.

12. Zhang $\mathrm{N}, \mathrm{Wu} \mathrm{P}, \mathrm{Wu} \mathrm{L}$, et al. The differential expression of vascular endothelial growth inhibitor isoforms, VEGI251, VEGI174 and VEGI192 in human clear-cell renal cell carcinoma. Cancer Genomics Proteomics. 2013;10:47-53.

13. Zhao Q, Liu T, Hong B, et al. Vascular Endothelial Growth Inhibitor, a Cytokine of the Tumor Necrosis Factor Family, is Associated With Epithelial-Mesenchymal Transition in Renal Cell Carcinoma. Applied immunohistochemistry \& molecular morphology: AIMM; 2017.

14. Jia W, Sander AJ, Jia G, et al. Vascular endothelial growth inhibitor (VEGI) is an independent indicator for invasion in human pituitary adenomas. Anticancer Res. 2013;33:3815-3822.

15. Slebioda TJ, Rowley TF, Ferdinand JR, et al. Triggering of TNFRSF25 promotes CD8(+) T-cell responses and anti-tumor immunity. Eur J Immunol. 2011;41:2606-2611.
16. Zhang Z, Yu D, Lu J, et al. Functional genetic variants of TNFSF15 and their association with gastric adenocarcinoma: a case-control study. PLoS ONE. 2014;9:e108321.

17. Sun Y, Irwanto A, Toyo-Oka L, et al. Fine-mapping analysis revealed complex pleiotropic effect and tissue-specific regulatory mechanism of TNFSF15 in primary biliary cholangitis. Crohn's disease and leprosy. Sci Rep. 2016;6:31429.

18. Ye BD, Choi H, Hong M, et al. Identification of ten additional susceptibility loci for ulcerative colitis through immunochip analysis in Koreans. Inflamm Bowel Dis. 2016;22:13-19.

19. Kepiro L, Szell M, Kovacs L, et al. Genetic risk and protective factors of TNFSF15 gene variants detected using single nucleotide polymorphisms in Hungarians with psoriasis and psoriatic arthritis. Hum Immunol. 2014;75:159-162.

20. Simon K. Colorectal cancer development and advances in screening. Clin Interv Aging. 2016;11:967-976.

21. Boland CR, Goel A. Microsatellite instability in colorectal cancer. Gastroenterology. 2010;138:2073-2087.e3.

22. van de Velde CJ, Boelens PG, Borras JM, et al. EURECCA colorectal: multidisciplinary management: European consensus conference colon \& rectum. Eur J Cancer. 2014;50:1.e1-1.e34.

23. Park MH, Song MJ, Cho MC, et al. Interleukin-32 enhances cytotoxic effect of natural killer cells to cancer cells via activation of death receptor 3. Immunology. 2012;135:63-72.

24. Boland CR, Thibodeau SN, Hamilton SR, et al. A National Cancer Institute Workshop on Microsatellite Instability for cancer detection and familial predisposition: development of international criteria for the determination of microsatellite instability in colorectal cancer. Can Res. 1998;58:5248-5257.

25. Wierzbicki PM, Adrych K, Kartanowicz D, et al. Underexpression of LATS1 TSG in colorectal cancer is associated with promoter hypermethylation. World J Gastroenterol. 2013;19:4363-4373.

26. Janavicius R, Matiukaite D, Jakubauskas A, Griskevicius L. Microsatellite instability detection by high-resolution melting analysis. Clin Chem. 2010;56:1750-1757.

27. Weidner N. Angiogenesis as a predictor of clinical outcome in cancer patients. Hum Pathol. 2000;31:403-405.

28. Bittner S, Knoll G, Ehrenschwender M. Death receptor 3 signaling enhances proliferation of human regulatory $\mathrm{T}$ cells. FEBS Lett. 2017;591:1187-1195.

29. Karin M. NF-kappaB as a critical link between inflammation and cancer. Cold Spring Harb Perspect Biol. 2009;1:a000141.

30. Maisey N. Antitumor necrosis factor (TNF-a) antibodies in the treatment of renal cell cancer. Cancer Invest. 2007;25:589-593.

31. Harrison ML, Obermueller E, Maisey NR, et al. Tumor necrosis factor alpha as a new target for renal cell carcinoma: two sequential phase II trials of infliximab at standard and high dose. J Clin Oncol. 2007;25:4542-4549.

32. Balkwill F. TNF-alpha in promotion and progression of cancer. Cancer Metastasis Rev. 2006;25:409-416.

33. Pikarsky E, Porat RM, Stein I, et al. NF-kappaB functions as a tumour promoter in inflammation-associated cancer. Nature. 2004;431:461-466.

34. Moorchung N, Kunwar S, Ahmed KW. An evaluation of nuclear factor kappa B expression in colorectal carcinoma: an analysis of 50 cases. J Cancer Res Ther. 2014;10:631-635.

35. Niu W, Wu Z, Wang J, et al. Tumor necrosis factor ligand-related molecule $1 \mathrm{~A}$ regulates the occurrence of colitis-associated colorectal cancer. Dig Dis Sci. 2018;63:2341-2350. https://doi. org/10.1007/s10620-018-5126-0.

36. Gout S, Morin C, Houle F, Huot J. Death receptor-3, a new E-Selectin counter-receptor that confers migration and survival advantages to colon carcinoma cells by triggering p38 and ERK MAPK activation. Can Res. 2006;66:9117-9124.

37. Zhang L, Zhang Y, Zhang L, Yang X, Lv Z. Lupeol, a dietary triterpene, inhibited growth, and induced apoptosis through 
down-regulation of DR3 in SMMC7721 cells. Cancer Invest. 2009;27:163-170.

38. Ge Z, Sanders AJ, Ye L, Mansel RE, Jiang WG. Expression of death receptor- 3 in human breast cancer and its functional effects on breast cancer cells in vitro. Oncol Rep. 2013;29:1356-1364.

39. Baskaran K, Pugazhendhi S, Ramakrishna BS. Protective association of tumor necrosis factor superfamily 15 (TNFSF15) polymorphic haplotype with Ulcerative Colitis and Crohn's disease in an Indian population. PLOS ONE. 2014;9:e114665.

40. Connelly TM, Choi CS, Berg AS, et al. Diverticulitis and Crohn's disease have distinct but overlapping tumor necrosis superfamily 15 haplotypes. J Surg Res. 2017;214:262-269.

41. Hedl M, Abraham C. A TNFSF15 disease-risk polymorphism increases pattern-recognition receptor-induced signaling through caspase-8-induced IL-1. Proc Natl Acad Sci USA. 2014;111:13451-13456.

42. Bamias G, Martin C 3rd, Marini M, et al. Expression, localization, and functional activity of TL1A, a novel Th1-polarizing cytokine in inflammatory bowel disease. J Immunol. 2003;171:4868-4874.

43. Zhang E, Zhu X, Han S, et al. Increased expression of TNF ligandrelated molecule $1 \mathrm{~A}$ and death receptor 3 in bladder tissues of patients with painful bladder syndrome/interstitial cystitis. Exp Ther Med. 2013;5:282-286.

Publisher's Note Springer Nature remains neutral with regard to jurisdictional claims in published maps and institutional affiliations. 